\title{
Laparoscopic extirpation of a fork from the duodenum
}

\author{
W. K. Karcz • B. Kulemann • G. J. Seifert • \\ H. J. Schrag · S. Küsters · G. Marjanovic • \\ J. M. Grüneberger $\cdot$ A. Braun
}

Received: 21 March 2010/Accepted: 26 July 2010/Published online: 17 March 2011

(C) Springer Science+Business Media, LLC 2011

\begin{abstract}
Background A 23-year-old woman who 2 weeks before visiting our institution swallowed a plastic fork while attempting to induce vomiting during a party presented with progressive abdominal pain. Various techniques for removing foreign bodies from the intestinal tract have been described. We present the laparoscopic retrieval of a $15-\mathrm{cm}$ fork from the duodenal bulb.

Methods The patient presented with leukocytosis and epigastric tenderness. An upper endoscopy revealed a plastic fork, tines up, perforating the duodenal bulb. The handle was irremovably lodged in the opposite part of the duodenum. Perforating objects and objects larger than $7 \mathrm{~cm}$ ought to be removed surgically to prevent esophageal perforation. The patient was placed in supine position with the surgeon standing between her legs. Four trocars, two 10-mm and two 5-mm, were used. We saw a slight swelling of the duodenum with few fibrin stripes and roughly $250 \mathrm{ml}$ of white exudate. The fork tines were
\end{abstract}

W. K. Karcz and B. Kulemann contributed equally to this work.

Presented at the 12th WCES, April 14-17, 2010, National Harbor, MD.

Electronic supplementary material The online version of this article (doi:10.1007/s00464-010-1533-9) contains supplementary material, which is available to authorized users.

W. K. Karcz · B. Kulemann ( $\square) \cdot$ G. J. Seifert ·

H. J. Schrag · S. Küsters · G. Marjanovic .

J. M. Grüneberger · A. Braun

Interdisciplinary Centre for Metabolic and Obesity Surgery,

Videosurgery Division, Department of General and Abdominal

Surgery, University Hospital Freiburg, Hugstetter Strasse 55,

79106 Freiburg, Germany

e-mail: birte.kulemann@uniklinik-freiburg.de visible; there were no injuries to the liver. The tines were held with a clamp while the perforated intestinal wall was carefully dissected with a monopolar hug and later with an ACE harmonic scalpel due to bleeding. The fork was extracted in the proximal direction through the perforation injury. There was no severe necrosis and debridement was not necessary. The bowel was irrigated and continuously sutured with 3-0 PDS. Finally, the fork was retrieved through the $10-\mathrm{mm}$ trocar incision.

Results Operating time was $60 \mathrm{~min}$ and blood loss was roughly $100 \mathrm{ml}$. The patient's postoperative course was uneventful. One year after intervention, the patient is doing well.

Conclusion A fork may be swallowed, but usually does not spontaneously pass through the gastrointestinal tract. Early removal should be advised to avoid perforation and to minimize morbidity. Laparoscopic removal is a safe and feasible method of managing foreign bodies that are not removable endoscopically.

Keywords Foreign body - Perforation duodenum . Laparoscopic removal

Disclosures W. K. Karcz, B. Kulemann, G. J. Seifert, H. J. Schrag, S. Küsters, G. Marjanovic, J. M. Grüneberger, and A. Braun have no conflicts of interest or financial ties to disclose. 